\title{
El Parque Saavedra de Comodoro Rivadavia: patrimonio paisajístico etnografiado
}

\author{
Comodoro Rivadavia's Saavedra Park: \\ An ethnographic landscape heritage \\ Dra. Graciela Ciselli \\ Universidad Nacional de la Patagonia San Juan Bosco, Argentina \\ Académico Departamento de Trabajo Social \\ graciselli@hotmail.com [orcid.org/0000-0002-3653-8262]
}

\section{RESUMEN}

El Parque Saavedra, construido en 1937, es un componente de las redes creadas por la Empresa estatal Yacimientos Petrolíferos Fiscales descubridora del petróleo en 1907 en la Patagonia argentina que se mantuvieron hasta su privatización en los noventa. Durante este último proceso sus bienes fueron transferidos a la Municipalidad de Comodoro Rivadavia, quien los entregó en comodato a un ente gremial en 2005 motivando acciones judiciales, aunque desestimadas, impulsaron su declaratoria como patrimonio cultural de la ciudad en 2008. El artículo analiza el Parque en su doble carácter como: referente de identidades sociales construidas históricamente al amparo de Y.P.F. y patrimonio paisajístico protegido.

PALABRAS CLAVE: paisaje, derechos, etnografía, identidad.

\begin{abstract}
The Saavedra Park, built in 1937, is a component of the networks created by the state oil company Y.P.F., which discovered oil in 1907 in Argentine Patagonia, and that endured until its privatization in the nineteen nineties. During this last process, their assets were transferred to the Municipality of Comodoro Rivadavia, who handed it over as a commodate to a trade union in 2005, motivating legal actions, although dismissed, that prompted its declaration as cultural heritage of the city in 2008. The article analyzes the Park in its double nature as: reference of social identities historically constructed under the umbrella of Y.P.F. and as landscape heritage.
\end{abstract}

KEY WORDS: landscape, laws, ethnography, identity. 


\section{INTRODUCCIÓN}

Desde el descubrimiento del petróleo en Comodoro Rivadavia en el año 1907, la empresa estatal (conocida desde 1922 como Yacimientos Petrolíferos Fiscales o su sigla Y.P.F.) organizó todas las esferas de la vida institucional empresarial y de la vida cotidiana de los trabajadores de modo acorde a los requerimientos de la industria, una de las más importantes de la Argentina. Así fue como se generaron redes sociales, educativas, recreativas y laborales que fueron construyendo identidades sociales en estrecha relación con la propia historia de la empresa y el sistema productivo petrolero. La construcción del Parque Saavedra de Comodoro Rivadavia ejemplifica una de esas redes: la recreativa.

El tipo de trabajo petrolero al que los hombres debían dedicarse con "cerebro, corazón y músculo”, según las propias palabras del Gral. Enrique Mosconi -primer director de Y.P.F.-, demandaba cierto control disciplinario que se ejercitaba a través de diversos aspectos que iban más allá del espacio laboral. El tiempo libre y las actividades deportivas y recreativas eran parte de una estrategia que permitía mantener a los obreros ocupados y alejados de las actividades políticas o de los reclamos sindicales, además de estimular la creación de lazos comunitarios al interior del sistema productivo que fueron construyendo la identidad ypefeana.

En su despliegue territorial de exploración y explotación petrolera, la empresa creó el Campamento Central donde asentó el corazón administrativo y laboral de aquélla en torno al pozo descubierto en 1907 y generó campamentos próximos a los nuevos pozos para facilitar la dinámica laboral. Así se originó el Barrio General Saavedra en los años veinte para familias obreras y en 1937 se inició la construcción del Parque "Cornelio Saavedra”, de unas 24 hectáreas, en el extremo sur del barrio y contiguo al pozo 363.

La construcción del Parque como espacio para el ocio y el descanso fue encomendada a la Comisión de Parques y Jardines de Y.P.F. que eligió un valle rodeado de mesetas, un lugar protegido que eliminaría el efecto del viento patagónico y serviría para el esparcimiento, próximo a la zona de trabajo y a los hogares de los trabajadores. La empresa construyó un parque exquisitamente diseñado, dentro de un estilo mixto entre el geometrismo rígido francés y el sentimentalismo romántico inglés de las curvas y sorpresas, destacándose un laberinto con tamariscos que formaba la sigla Y.P.F. que podía divisarse desde los cerros circundantes.

Ya en la vista de su construcción hubo una preocupación por mostrar el lugar estratégico de la obra, a partir de lo que se puede inferir la valoración que le dio la propia empresa por más de treinta años al destinarla de modo exclusivo al bienestar de los ypefeanos y sus familias, generando sentimientos y percepciones que aún perduran en la memoria de los viejos pobladores.

Desde 1969 el acceso a algunos sectores del predio se liberó para el libre disfrute de la población comodorense con la entrega en comodato al municipio. Los concejales de 
1973 al referirse al Parque ya lo resaltaban como un elemento identitario de la comunidad comodorense, remarcando su valor histórico, paisajístico y natural.

Los vaivenes en la vida institucional política nacional, en el pasaje de un gobierno populista a dictaduras militares, hicieron mella en la vida comunitaria de los comodorenses interrumpiendo el proceso de construcción de identidades sociales en torno a la resignificación del Parque como bien de uso público. Con la vuelta a la democracia en los ochenta, la situación no se modificó y el proceso de desmembramiento del Parque en sectores ofrecidos para diversos usos (hasta un minizoológico) influyó en la pérdida del ideal estético paisajístico original. A mediados de los noventa se produjo la transferencia de todo el predio en forma definitiva al Estado Municipal tras la privatización de Y.P.F.

Cuando en 2003 el municipio inició una política de promoción de espacios verdes, el Centro de Empleados de Comercio presentó el "Proyecto de recuperación del Parque Saavedra”. Desde una perspectiva utilitaria -de reforestar para pasar un día de campo- se firmó un comodato entre ambos en 2005 que fue aprobado en 2006. El convenio provocó reacciones, reflexiones y valoraciones de ex ypefeanos, convirtiéndolo en objeto de mirada y de disputa simbólica y legal.

Mientras la Comisión Evaluadora de Patrimonio Histórico, Cultural y Natural de la ciudad catalogaba al Parque Saavedra como paisaje cultural en un doble sentido: como referente identitario de los ypefeanos y por su valor patrimonial; una vecina presentaba una acción de amparo ante el Convenio de Comodato. La disputa legal tuvo dos aspectos: uno negativo por la desestimación de dicha acción por parte del juez en 2007, pero uno positivo que fue la declaratoria municipal como patrimonio cultural de la ciudad en 2008.

Más allá de la continuidad del Convenio de Comodato hasta el año 2042, el Parque constituye un paisaje urbano de jurisdicción municipal que está siendo, lentamente, incorporado en la agenda política y en el debate sobre el territorio. Su carácter de Patrimonio Histórico, Cultural y Natural de la ciudad de Comodoro Rivadavia requiere de una interpretación jurídica dado que la Constitución Nacional Argentina, desde la Reforma de 1994, considera la preservación del patrimonio cultural como un derecho con el mayor rango de protección asimilable al derecho a un ambiente sano.

El artículo se centra en el Parque Saavedra en su carácter de referente de identidades sociales en disputa entre aquellas construidas históricamente bajo la sigla de la empresa petrolera estatal Y.P.F. y las actuales; su valoración como paisaje cultural y la aplicabilidad del sistema normativo ante su declaratoria como patrimonio paisajístico. En este pasaje de objeto identitario a objeto jurídico se ha recurrido al trabajo de campo antropológico en clave histórica y al análisis interpretativo de la normativa legal.

\section{METODOLOGÍA}

El Parque Saavedra es la situación problemática que sirve para discutir la noción patrimonio paisajístico con los aportes de la hermenéutica jurídica, en cuanto se interpreta el derecho para 
comprenderlo y aplicarlo. El Parque es significativo no sólo como referente empírico sino como estrategia metodológica para discutir la aplicabilidad de la categoría patrimonio paisajístico y su inserción en el sistema jurídico ambiental. Su etnografía puede ser utilizada como ejemplo para describir y valorar otros bienes culturales ambientales (Fig. 1).

Cuando se indaga en la valoración social de los bienes culturales, la etnografía ${ }^{1}$ es el enfoque más adecuado ya que permite recuperar una multiplicidad de voces: los políticos, los visitantes, los vecinos que refieren a sus usos, su historia vivida y sus percepciones. El Parque es susceptible de una descripción densa por sus características paisajísticas, su historicidad y sus usos sociales. La descripción densa/etnográfica es una herramienta metodológica que puede ser utilizada para describir y valorar bienes culturales ambientales e ilustrar conceptos teóricos que interesan a la ciencia en contextos cotidianos y pequeños (Geertz, 2000), con sus descripciones detalladas, circunstanciadas y a pequeña escala, similares a los casos judiciales.

El material empírico que se analiza fue recabado durante el trabajo de campo donde se realizaron 10 entrevistas semi estructuradas a ex ypefeanos. Mirar y oír, en palabras del antropólogo Cardoso de Oliveira (2004), formaron parte de una primera etapa en la cual la percepción (a través de la observación) y la escucha “disciplinada” (entrevistas) guiaron el trabajo de campo y facilitaron la comprensión del significado que los habitantes de los barrios vinculados a Y.P.F. le daban a ese bien cultural marcado por la privatización de la empresa estatal y cómo ha sido resignificado por sus usuarios a partir de ese momento.

La “sacralización”, puesta en valor del Parque y activación (Prats, 1997) forman parte del "proceso de patrimonialización" en el cual se interrelacionan componentes sociales, políticos y jurídicos. De ahí la importancia de conocer la valoración de sus aspectos patrimoniales por parte de los diversos actores sociales y políticos. Su declaratoria como patrimonio cultural con la tipología de paisaje cultural lo convierten en caso singular para el análisis jurisprudencial. La pregunta que se busca responder es: ¿Resulta aplicable el artículo 41 de la Constitución Nacional para proteger el Parque Saavedra declarado patrimonio cultural, en su expresión paisajística, con las herramientas que brinda el del sistema jurídico ambiental argentino?

Por último, cabe mencionar que junto con las técnicas propias del trabajo de campo se analizó doctrina, legislación y jurisprudencia relacionada con el patrimonio cultural y fuentes históricas y fotográficas que permiten interpretar ese universo microhistórico constituido por el Parque Saavedra. Una cronología del Parque Saavedra ayuda a comprender el proceso (Fig. 2).

\footnotetext{
La antropóloga R. Guber $(2001,2004)$ plantea una triple acepción de la palabra. Como método, la etnografía es el conjunto de actividades conocidas como "trabajo de campo" y cuyo resultado se emplea como evidencia para la descripción. Son los actores los privilegiados para expresar en palabras y en prácticas el sentido de su vida y su cotidianeidad. Como enfoque, busca comprender los fenómenos sociales desde la perspectiva de sus miembros respondiendo a preguntas sobre qué, por qué ha ocurrido y qué significa para ellos. Como texto donde se vuelca el estudio monográfico realizado.
} 


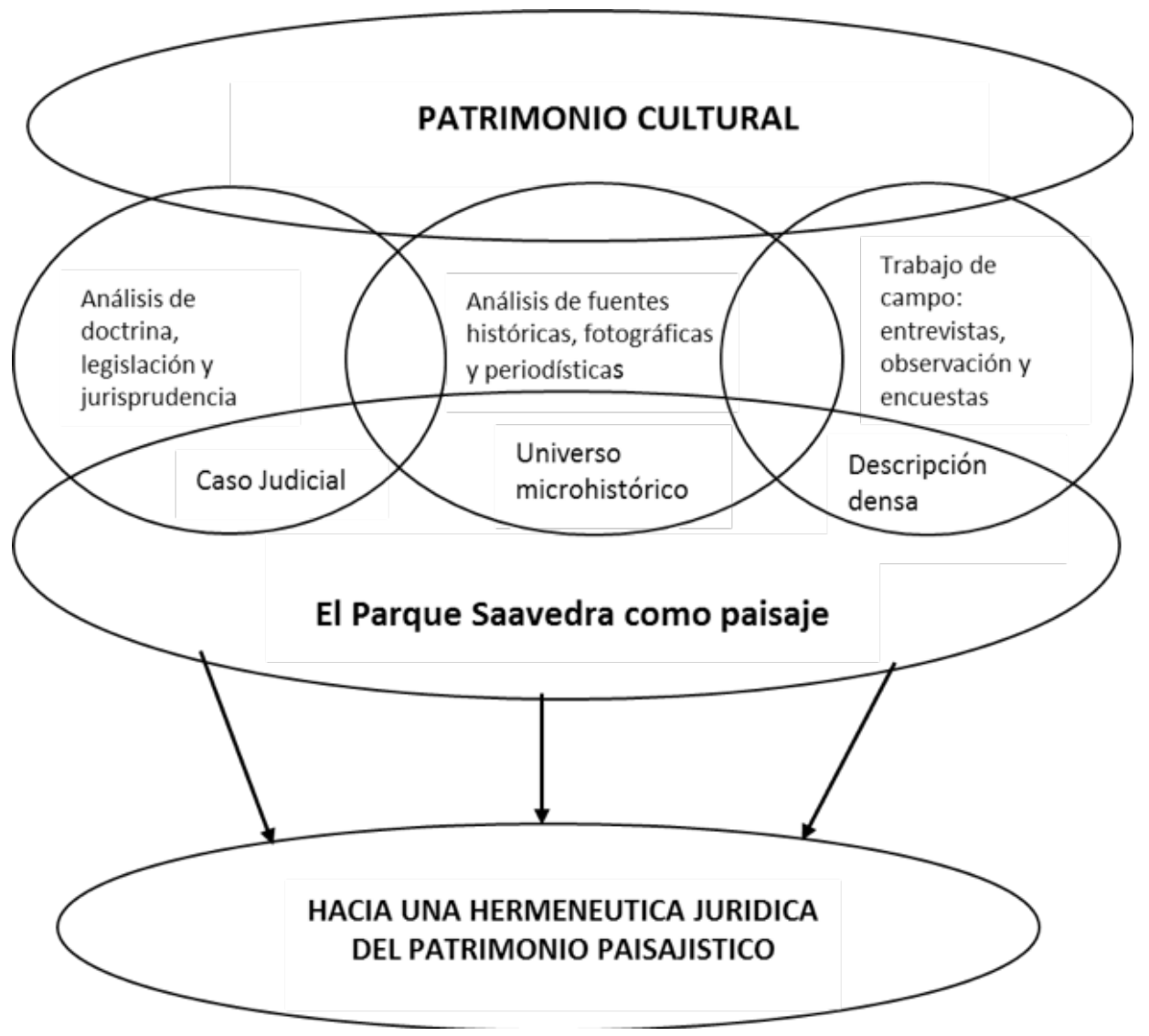

Fig. 1. De la disciplina a la interdisciplina. Fuente: Elaboración propia.

De paisaje cultural a patrimonio paisajístico

La palabra paisaje proviene del latín pagensis, paesaggio, campestre y del francés pays, espacio rural (Santos \& Ganges, 2003, p. 42). El paisaje nació como categoría geográfica y fue receptada por otras Ciencias Sociales como la Antropología y la Historia, pero pasó inadvertida para el Derecho hasta que comenzó a sufrir alteraciones con el urbanismo y la industrialización que exigieron su tutela ante la contaminación y degradación ambiental. En tanto es una categoría construida extrajurídicamente muestra su utilidad para la protección jurídica de un bien cultural-ambiental vinculado a la identidad de la población en un territorio determinado (Ciselli, 2018).

El interés científico por el paisaje se introdujo en el ordenamiento jurídico a través de la conservación ambiental en las décadas de 1970 y 1980 y en la década siguiente la discusión avanzó hacia la gestión sostenible del paisaje que sirvió como antecedente del Convenio Europeo del Paisaje (Florencia, 2000). Este documento resulta de valor interpretativo para el análisis del Parque Saavedra al permitir relacionar las categorías Patrimonio Cultural, Ambiente y Ordenamiento Territorial. 
Las actuales definiciones del paisaje tienden a reconocer su valor como bien cultural que puede ser activado como patrimonio cultural, por lo cual han resurgido las temáticas paisajísticas en sus diversas manifestaciones (Serrano, 2007). El paisaje local, definido como "cualquier parte del territorio tal como lo percibe la población, cuyo carácter sea el resultado de la acción y la interacción de factores naturales y/o humanos", tal como lo define la Convención Europea del Paisaje (Florencia, 2000), cobra sentido frente a la globalización, a la crisis identitaria que ha generado y también a sus activaciones en la revaloración de lo local.

El paisaje nace de la relación y la percepción sensorial de quienes habitan y observan el territorio con toda la complejidad psicológica y cultural que implica la percepción, desde los aspectos visuales a los relacionados con la experiencia estética de la contemplación reflexiva (Mata Olmo, 2009). Esta carga cultural del paisaje se expresa a partir de miradas múltiples y cambiantes en el tiempo, que se manifiestan materialmente en cada lugar modelado por la acción humana, como en sus imágenes y representaciones sociales.

La percepción también remite a la política, dado que la participación social constituye la vía para conocer -según el Convenio- "las aspiraciones de las poblaciones" en materia de paisaje y la formulación de los denominados "objetivos de calidad paisajística”. Si el Convenio de Florencia insiste tanto en la cuestión participativa -dice Prieur (2011)- es para traducir jurídicamente la especificidad del 'paisaje' del mejor modo posible. El especial interés en el "paisaje ordinario" o cotidiano se relaciona con la construcción de un derecho al paisaje de la gente.

El paisaje patrimonial sostenible implica, en términos del Convenio Europeo: la protección de ciertos paisajes y ecosistemas antrópicos, una adecuada gestión teniendo en cuenta los valores subjetivos de la población y el reconocimiento de que el paisaje forma parte de un proceso sociohistórico que no puede desconocerse y que marca la trilogía que conecta el pasado con el presente y le da sentido a su protección futura. Es decir que se mira el paisaje como el resultado de la relación dialéctica entre los componentes bióticos a lo que se suma la interpretación que el habitante realiza del paisaje percibido. Un paisaje que lo identifica y proporciona pertenencia, que debe ser conservado y protegido como elemento identitario de una determinada comunidad; idea que lleva a reconocer al paisaje con valor patrimonial para protegerlo. Por lo cual es considerado un recurso natural, cultural y económico y como tal debe ser también ordenado y gestionado.

Ya que el paisaje requiere de mecanismos protectorios entra en juego el campo jurídico no sólo al catalogarlo de patrimonial (por ejemplo, inventariándolo) sino también cuando lo declara formalmente para que goce de la máxima protección legal. Ahora bien, declararlo patrimonio no implica congelarlo sino reconocer que el paso del tiempo y que también la gente actúa sobre él. Entre los posibles modos de asegurar que el patrimonio sea transferible a las generaciones futuras se encuentran las tareas de investigación que facilitan su protección, conservación y difusión. Pero no hay que olvidar los usos sociales de los 
bienes patrimoniales, pues para que siga manteniendo su valor patrimonial es necesario que sea apropiado por la gente que lo percibe y que lo vivencia (Ciselli, 2018).

Entonces cualquier intervención que se realice con el paisaje debe ser proyectual. Todo proyecto que narra la historia de un determinado paisaje forma parte de una postura ideológica, lo que implica que no estará exento de conflictos y pugnas de intereses por mostrar tal o cual historia. Lo importante sería entonces no hacer oídos sordos a las percepciones y sentimientos, a las vivencias y al proceso histórico que ha vivido esa comunidad y que son las huellas que han dejado en ese paisaje que es único e irrepetible.

Por ello, el paisaje como interfaz entre los problemas de la sociedad y del ambiente, permite profundizar en el conocimiento de la relación entre los procesos naturales, sociales, económicos y culturales y la aceptabilidad social de las transformaciones que estos procesos generan (Frolova, 2009). Se trata de una diversidad patrimonial, que no debe quedar eclipsada por la diversidad biológica, políticamente más asumida hasta ahora e integrada en el todo paisajístico (Mata Olmo, 2009, p. 160). Por lo antedicho, el paisaje hace referencia a "la cultura territorial" de un pueblo, siendo el resultado objetivo de la gestión cotidiana sobre el territorio y el modo en que cada sociedad organiza su espacio.

En este sentido, ha cobrado importancia el estudio de las representaciones que los grupos hacen de su territorio y de los modos en que perciben el paisaje cotidiano y construyen sus identidades territoriales. Es decir que estamos ante un paradigma que plantea el paisaje como noción cultural y científica vinculada a la calidad de vida de los grupos en un territorio; como un bien colectivo que compete tanto al Patrimonio Cultural como Natural y responde al interés por el desarrollo sostenible reivindicado en la Conferencia de Río 1992 (el subrayado es mío).

Es decir que territorio, paisaje y sostenibilidad, se manifiestan como tres conceptos interrelacionados que acompañan el avance del ordenamiento hacia un nuevo modelo territorial. Es una concepción basada en inquietudes respecto a cuestiones ambientales y culturales, con una motivación particularmente social y que se sostiene sobre tres nociones: territorio, percepción y carácter. La idea de carácter de cada paisaje es resultado de la interrelación entre factores naturales y humanos y hace referencia a la "señal o marca que se imprime en algo" y al "conjunto de cualidades o circunstancias propias de una cosa, o de una colectividad, que las distingue de las demás”. El sentido de carácter como seña o marca que se imprime en algo -en este caso en el territorio- incorpora el tiempo histórico y se acerca a la idea de "huella" planteada por Jean-Marc Besse (2006) como fisonomía del territorio. El paisaje es, en su configuración formal, la huella de la sociedad sobre la naturaleza y sobre paisajes anteriores, la marca o señal que imprime "carácter" a cada territorio (Mata Olmo, 2009), el resultado de la interacción hombre-naturaleza a través del tiempo.

Como parte de un proceso histórico, todo territorio merece la protección, gestión y valorización de su paisaje, superando así la visión elitista dominante que planteó por mucho tiempo la UNESCO y que ha predominado en la legislación de patrimonio histórico-artístico. 
El paisaje tiene una base material referida a territorio no sólo como espacio geográfico sino también como modo de vida construido socialmente en distintos contextos ambientales e históricos.

Desde un punto de vista jurídico, el poco interés por los derechos culturales (entre los que se considera el patrimonio cultural en sus diversas expresiones) obedece, principalmente, a las desigualdades de poder existentes en la sociedad lo que también explica la percepción devaluada y de subordinación que se tiene de ellos -concebidos como derechos débiles- en relación con otros derechos considerados fundamentales. Esta percepción no favorece la protección de los bienes colectivos a la hora de hacerlos valer, convirtiéndolos en no justiciables vs exigibles, en casos donde se pone en juego el derecho de propiedad privada. Es decir que son derechos proclamados en los textos jurídicos, pero poco efectivos en la práctica.

Por ello que es vital que cualquier legislación que se promueva vaya acompañada por una gestión patrimonial adecuada y comprometida por parte de los diversos actores políticos de los diferentes sectores y niveles del Estado, principalmente de los gobiernos locales, y sociales con miras a la previsión y planificación territorial que permita construir un sistema protectorio del paisaje, al menos esa parece ser la ambición para la Argentina. La idea de paisaje como bien colectivo que combina elementos físico-químicos, biológicos y humanos en interrelación que conforman un sistema con tres niveles: geosistema (ambiente), sociosistema (sistemas de producción y poder) y el sistema cultural como referente de identidades y significados que cargan de simbolismo al territorio y le imprimen carácter marcado por el modo en que cada sociedad organiza su espacio (Rodríguez, 1998), ha sido incorporada paulatinamente en el derecho argentino a partir del reconocimiento constitucional de la noción amplia de ambiente y de los tratados de derechos humanos que protegen derechos fundamentales como a la participación en la vida cultural ${ }^{2}$ y el derecho humano al ambiente.

Por lo antedicho, los modos en que las sociedades se apropian de su historia, de su patrimonio cultural y de su paisaje deben abordarse junto con los problemas que afectan a la calidad de vida, a la felicidad de los seres humanos y que abarca sistemas de protección del ambiente natural, rural, cultural y urbano (Lorenzetti, 2005).

\section{La historicidad del Parque Saavedra y su valor como referente identitario}

El Parque Saavedra fue diseñado por la Comisión de Parques y Jardines de la empresa petrolera estatal Y.P.F. como parte de una red de servicios educativos, recreativos, sociales y de la salud vinculados a un sistema productivo, el petrolero, que exigía de la contención de sus trabajadores y empleados en espacios aislados próximos a los pozos.

Ej. Declaración Americana de Derechos y Deberes del Hombre en su art. 13, la Declaración Universal de Derechos

Humanos en el art. 27, el Pacto Internacional DESC en el art. 15. 


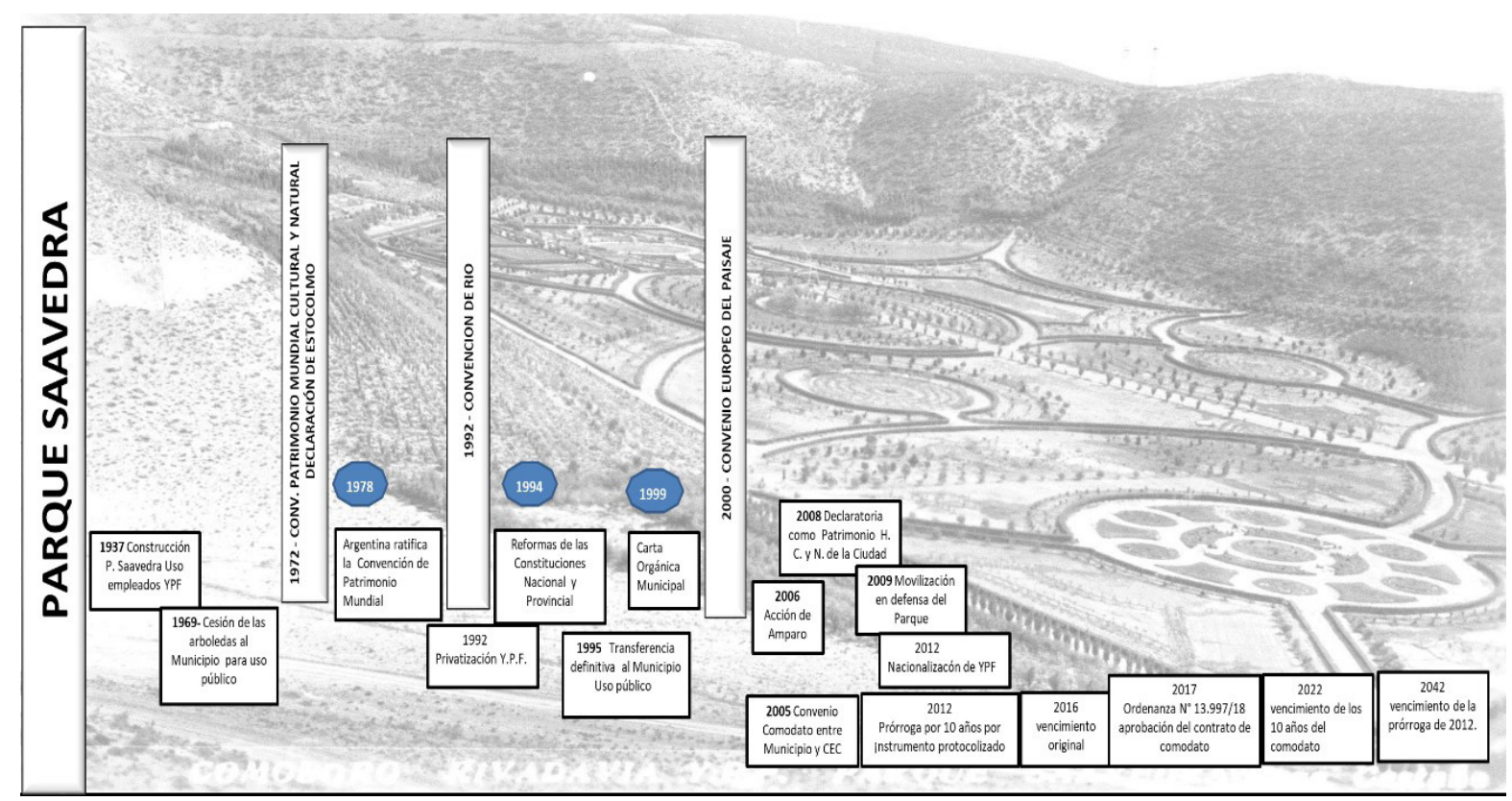

Fig. 2. Cronología del Parque Saavedra. Fuente: Elaboración propia.

Construido en 1937, en un valle rodeado de una cadena de cerros entre los que destacan el Hermitte (al norte) y el Vitteau (al sureste), un lugar protegido que eliminaría el efecto del viento y serviría como lugar de esparcimiento, próximo a la zona de trabajo y a los hogares de los trabajadores. Inspirado en el estilo mixto propio de los parques públicos franceses de la segunda mitad del siglo XIX e importado por el arquitecto, paisajista y urbanista francés Charles Thays (1849-1934) a la Argentina, cada sector con sus geometrías y sus curvas tenía un uso específico.

Esta panorámica tomada por la propia empresa (Fig. 3) muestra una torre en medio del Parque, la pequeñez de un hombre próximo al laberinto finamente geométrico con que se diseñó la sigla de Y.P.F. con plantaciones de tamariscos (Fig. 4, sector 19) para que pudiera verse desde los cerros circundantes, detalle del Parque que ha sido mantenido a través del tiempo, y más de una decena de torres petroleras asoman vigilantes sobre los cerros.

En el lateral sur y sudoeste del predio había dos viveros donde se preparaban plantines o aclimataban plantas para entregar a los trabajadores de la empresa. Con las flores que se cultivaban allí como calas, gladiolos, rosas, se diseñaban las palmas y coronas fúnebres y diversas ofrendas florales para los actos patrióticos o de la propia empresa que se corresponden con los sectores 18 (demolidos) y 11 (quemados) $^{3}$.

El sector 24 ubicado en las cercanías de la ladera este había sido destinado a jardín. Allí se sembraban plantas con flores: gladiolos, conejitos, pensamientos, claveles y en un costado

3 Entrevista a R.B, viuda del cuidador del Parque en los años 1950-1970, realizada en noviembre de 2015. 


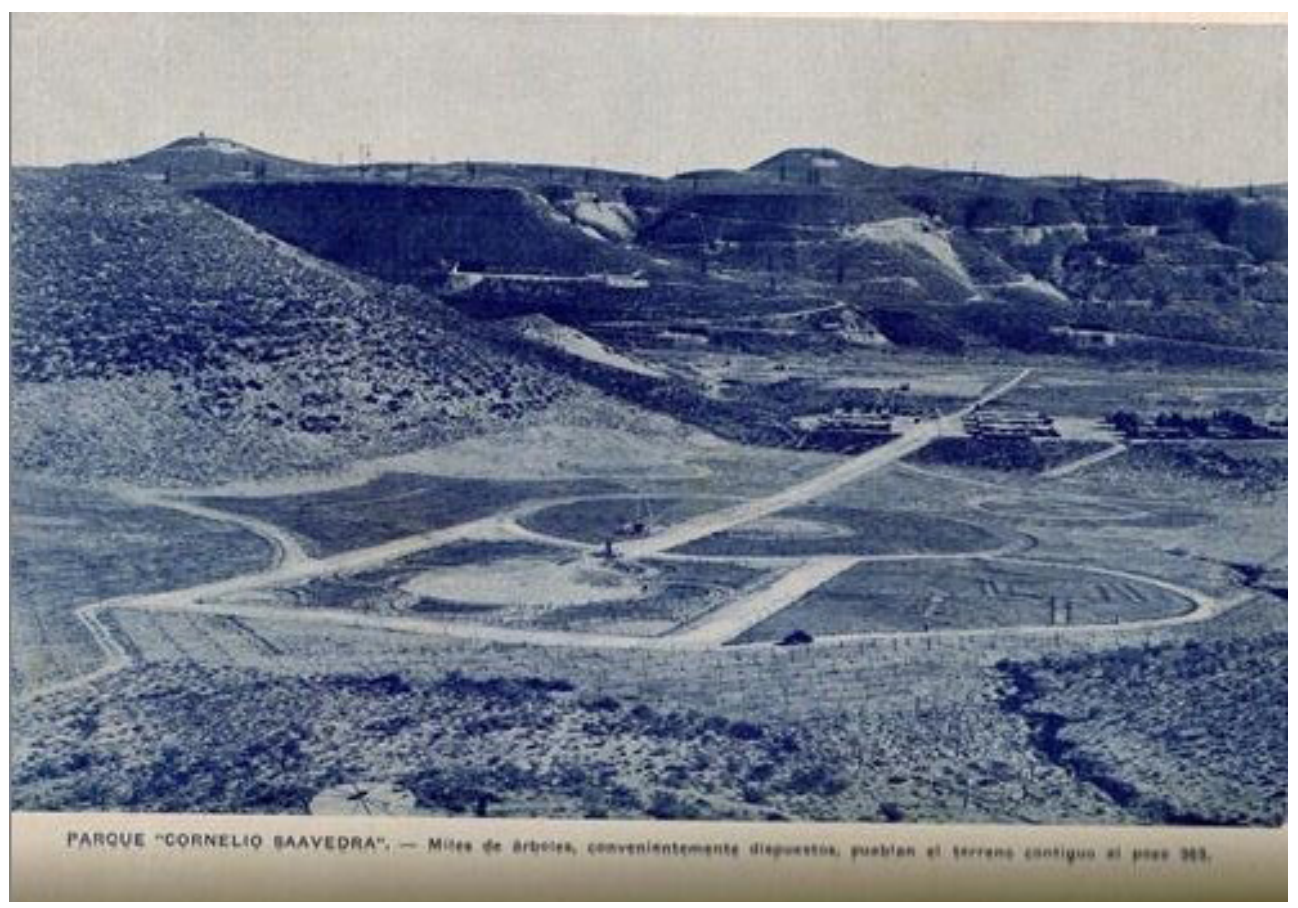

Fig. 3. El Parque construido en torno al pozo 363.

Fuente: Boletín de Informaciones Petrolíferas No 150, Y.P.F., 1937.

existía una glorieta ${ }^{4}$ de madera, redonda, con arcos de cemento tapados por enredaderas, rosales y moras, y rodeada de pinos que frecuentemente eran podados.

Otro de los sectores del Parque (sectores 4 y 25) estaba destinado a los fogones, canillas, mesas y asientos para los picnics. En un lateral del Parque (sector 21) estaba la caballeriza donde permanecía el caballo del recorredor de los pozos. Dos espacios de recreación estaban bien delimitados: la pista de baile al aire libre (sector 16), de forma cuadrangular se encontraba rodeada por numerosos bancos y mesas de cemento. Allí se realizaban las fiestas y tocaban música folclórica las orquestas locales o de trabajadores norteños, una fila de eucaliptos y tamariscos completaba el paisaje como un entorno envolvente de la pista de baile. Otro espacio (sector 6) estaba destinado al juego de los niños permitiendo el disfrute de distintas formas de esparcimiento, dejadas libradas a la imaginación: el laberinto entre los árboles, las caminatas, los contactos entre niños de distintos campamentos, los paseos con la escuela, las hamacas, los pasamanos, los subibajas, las moras y las frutas. El agua para el riego de los árboles provenía de dos tanques de aguas servidas que corría por diversas zanjas hechas a tal fin, mientras que para el pasto el riego era por aspersión. El agua potable que llegaba al Parque por medio de cañerías era reservada para el consumo de los visitantes en el sector picnic y para la vivienda del cuidador y su familia.

Espacio, generalmente redondo, en un jardín que se encuentra delimitado, cercado y vestido de plantas trepadoras, parras o árboles. 
Con los años, el Parque Saavedra se fue convirtiendo en un espacio de encuentro cotidiano entre los trabajadores y empleados, en un espacio para hablar, conquistar y disfrutar. Por más de 30 años fue un espacio exclusivo y gratuito de unas 6.800 personas entre obreros y empleados, quienes con sus familias ascendían a unas 17.000 personas en 1957 (Ezpeleta, 1957). Desde allí también se asesoraba acerca del cuidado de las plantaciones, métodos de prevención de plagas, poda de árboles, injertos y fertilizantes, a fin de contribuir con el embellecimiento de los pequeños jardines de las casas habitaciones y de los campamentos que poseía la empresa.

A principios de 1969, la Administración del yacimiento dispuso la apertura de un sector para los comodorenses cuando transfirió a título gratuito a la Municipalidad de Comodoro Rivadavia las arboledas, sembrados, lugares de camping y otras mejoras y cedía en comodato todas las demás instalaciones fijas ${ }^{5}$ con destino al uso público de la comunidad. Ya en manos del gobierno local, éste lo cedió en diversas oportunidades, con escasa suerte para el Parque.

Coincidentemente con la tercera vuelta del peronismo al gobierno nacional y con un Concejo Deliberante ${ }^{6}$ promotor de políticas de bienestar, el Parque Saavedra fue valorado como naturaleza transformada por el hombre con miras al uso recreativo de toda la población de la ciudad y presentado como elemento identitario de la comunidad comodorense, "testimonio de un pasado mejor", que "despierta sentimientos de amor y orgullo, de pertenencia a la tierra", pero también como un bien ambiental colectivo que tiene vida y es de todos, generando la obligación de cuidarlo, conservarlo y protegerlo.

Con temprana lucidez los concejales de 1973 remarcan su valor histórico, paisajístico y natural. Su conservación y protección se planteó en función de servir a la comunidad, destinado a la recreación visual y disfrute de la población comodorense y sobre el cual el Estado municipal se reconoció como responsable de su conservación y protección:

Al retornar al patrimonio municipal, el gobierno del pueblo debe asumir de inmediato la responsabilidad no sólo de salvar lo que queda sino de recrear lo que existió, ampliándolo y adecuándolo para que pueda cumplir la función de tipo social, recreativo y turístico que allí se puede desarrollar devolviéndole su antiguo esplendor.

Estas palabras se quedaron sin eco con la interrupción democrática en 1976. El sector del Parque destinado a uso público y al cuidado del municipio se deterioró con rapidez y aunque el resto del predio siguió en manos de Y.P.F., éste redujo el personal de mantenimiento de 40 a 4 en 1985, cuando el Parque fue dividido en sectores que fueron ofrecidos a diversas

5 Dirección de Patrimonio de la Municipalidad de Comodoro Rivadavia. Acta de suscripción entre Yacimientos Petrolíferos Fiscales y la Municipalidad de Comodoro Rivadavia del 14-8-1969.

6 Dirección de Patrimonio de la Municipalidad de Comodoro Rivadavia. Sesión ordinaria del Concejo Deliberante del 11 de diciembre de 1973 .

7 Archivo de la Dirección de Patrimonio Municipal. Sesión ordinaria del Concejo Deliberante del 11 de diciembre de 1973 . 


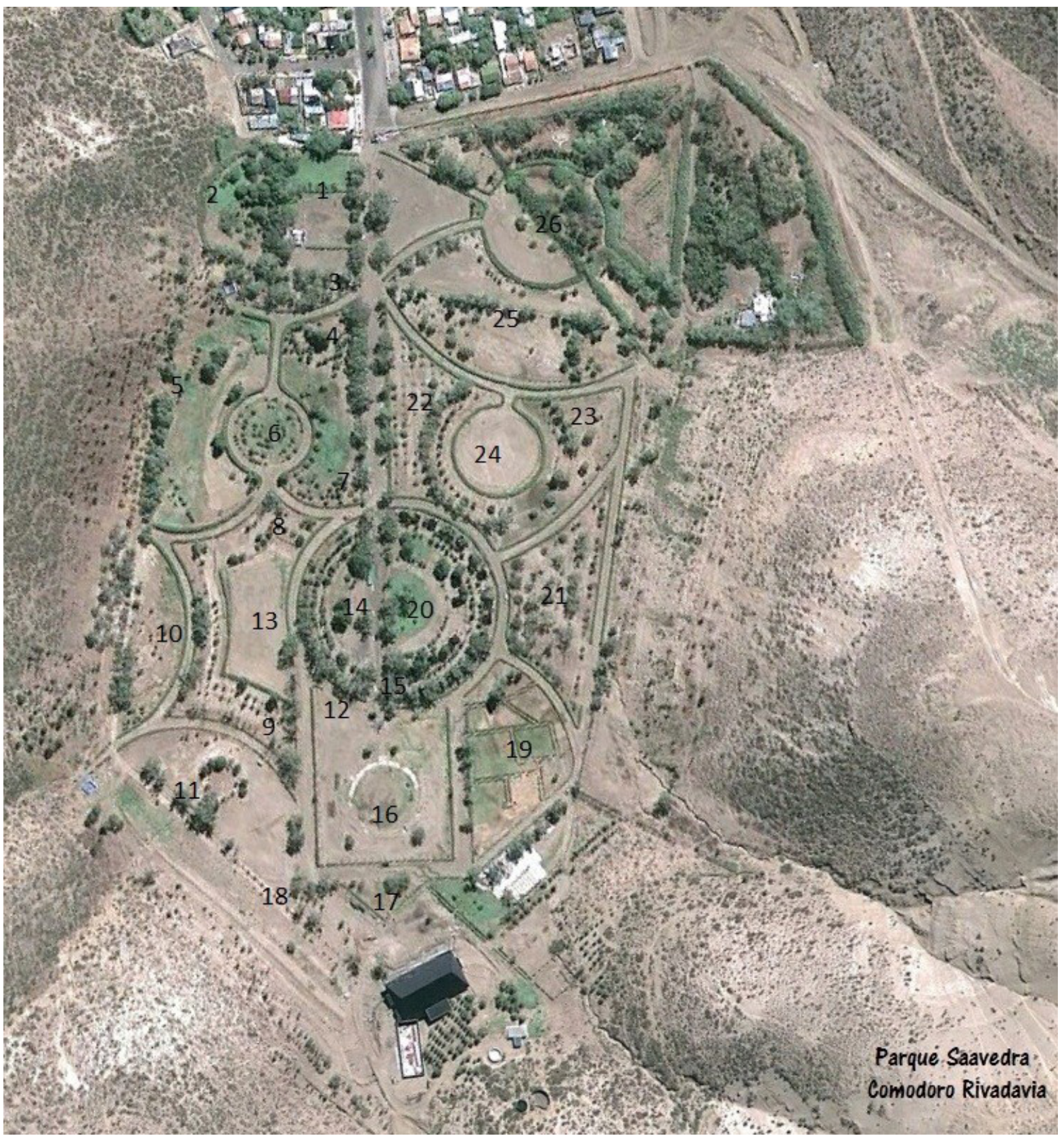

Fig. 4. Los sectores del Parque y sus usos sociales.

Fuente: Elaboración propia sobre la base de Google Earth, 2016.

entidades -sindicatos, mutuales, asociaciones vecinales y centros de jubilados de los barrios aledaños al Parque- para que cada una los usufructuara como les pareciera, situación que continuó durante los años 1990: albergue municipal para colonias de vacaciones, visitas educativas, proyecto de construcción de un jardín japonés que sería el segundo del país y de un mini zoológico. 
En noviembre de 1995, y en cumplimiento de lo dispuesto por la Ley 24.146, el Director Nacional de Bienes del Estado procedió a la transferencia definitiva y a título gratuito de diversos derechos y acciones sobre inmuebles del Estado Nacional Argentino (en manos de Y.P.F.) a favor de la Municipalidad local para ser afectados al uso público. El Parque Saavedra fue uno de esos bienes transferidos ${ }^{8}$ y la Municipalidad mantuvo el criterio de seguir ofreciéndolo en comodato para su explotación.

La reestructuración empresarial contrajo el mercado laboral lo cual implicó la expulsión de la población trabajadora del yacimiento estatal, el retorno de los migrantes a sus lugares de origen, la desaparición de un proyecto familiar y de vida que, en algunos casos, llevaba tres y hasta cuatro generaciones. La idea de "comunidad ypefeana" entró en una profunda crisis ante la desaparición del modelo protector y las políticas de bienestar que había implementado la empresa por más de 80 años. El Parque Saavedra formaba parte de ese sistema que, para esta época, era abierto sólo algunos fines de semana.

Una etapa de revalorización de esos espacios se activó a inicios del siglo XXI por parte de un grupo de actores sociales con pedidos de declaratorias de patrimonio e incluso con movilizaciones para impedir la venta de algunos edificios y espacios simbólicos. Puntualmente en diciembre de 2009 se difundió un volante firmado por Asociación Vecinal de Km 3 y B ${ }^{\circ}$ Saavedra, Asociación “Detrás del puente” Km 5, UNPSJB - SACORI (arquitectos), CPIAA (ingenieros), acompañado por una movilización en contra de las obras edilicias que el gremio había encarado en el marco del proyecto de recuperación del Parque Saavedra9 .

En los relatos, los entrevistados ponen en valor el Parque desde los afectos, la historia vivida, la historia compartida como ypefeanos o como habitantes del barrio Saavedra. Quienes provenían de familias ypefeanas describen el Parque como un "paseo de descanso", un "lugar para el picnic”, "donde oír el sonido de los árboles y los pájaros”, “disfrutar los juegos del Parque", "ver gente comiendo asado", "un paseo entre el laberinto de tamariscos que formaba la sigla Y.P.F.”. En ellos existe una identificación entre el barrio y el Parque, y entre éste y sus historias de vida:

Saavedra y el Parque siempre fue una sola cosa. El Parque era nuestra vida, desde el Jardín (de infantes) nos llevaba Y.P.F [...] Cuando lo clausuraron sentí que lo $\operatorname{perdíamos}^{10}[\ldots]$

8 Dirección de Patrimonio de la Municipalidad de Comodoro Rivadavia. Expte. 001-002202/94 del Ministerio de Economía y Obras y Servicios Públicos. Acta de notificación y entrega de la posesión.

9 Para ampliar sobre las movilizaciones puede consultarse el artículo de Ciselli y Enrici (2012). "En torno al valor histórico-paisajístico del Patrimonio Cultural. El caso del Parque Saavedra en Comodoro Rivadavia" en Revista de Historia Pasado Por-venir, 6. FHCS. UNPSJB y el capítulo IV. "El derecho constitucional al patrimonio cultural. La movilización ciudadana como recurso frente al Estado Municipal” en Ciselli, G. y Hernández, M. (2015). El patrimonio industrial como la huella del trabajador petrolero en el territorio. El caso de Y.P.F. en Comodoro Rivadavia y su impronta cultural. Buenos Aires. Ed. Dunken.

10 Entrevista realizada a M.T., habitante nacido y criado en el barrio, septiembre de 2013. 
También aparecen en ellos algunos intentos realizados por los socios del Club de Fútbol General Saavedra y por los habitantes del barrio para conseguir ellos el comodato, sin éxito:

El Club Saavedra pidió el Parque hacia 1999 para hacer la cancha y el club social [...] fueron tratativas que quedaron en palabras...El CEC aprovechó esa idea y lo pidió [...] si mejora la infraestructura para pasar el día es distinto, no para un fin económico propio...Ni idea cuánto invirtió [...] me gustan los quinchos individuales para ir con la familia, que sea más verde, pero no tener que pedir turno, de algo que era nuestro, tener que pagar ${ }^{11}$.

Quienes en la actualidad utilizan el Parque lo describen como un espacio para "disfrutar en familia y al aire libre", "compartir el asado familiar en los campings y paseos que tiene" o "es importante que los comodorenses se apropien del Parque como espacio destinado a la recreación"12.

\section{Su valoración como patrimonio paisajístico}

Desde 1989 existen antecedentes que colocan al Parque Saavedra como un elemento valorado por su potencial patrimonial. En esta fecha, ante la posibilidad de reformular el Código de Edificación Municipal, fue colocado entre los 6 hitos naturales de importancia en la ciudad; en 1991 el Código Ecológico Municipal lo consideró patrimonio paisajístico urbano y en 2005, la Comisión Evaluadora de Patrimonio emitió un Primer Informe específico sobre el Parque, fundamentando su valor como

paisaje cultural (Fig. 5), pues combina trabajos de la naturaleza y de la humanidad que expresan la íntima relación entre la sociedad y su ambiente natural... Los paisajes culturales testifican el genio creativo del hombre, el desarrollo social y la vitalidad de la humanidad. Ellos son parte de nuestra identidad colectiva ${ }^{13}$.

Desde el punto de vista normativo, la Convención de Patrimonio Mundial Cultural y Natural (París, 1972) es el primer instrumento internacional protectorio de los "monumentos, conjuntos y lugares" incorporado a la Argentina por Ley 21836/1978. Si bien en la referencia al valor estético de los lugares está implícita la noción de paisaje, es en la última década del siglo XX cuando se incorpora la noción paisaje cultural de modo explícito en las Directrices Operativas de esta Convención.

\footnotetext{
Entrevista realizada a J. B. noviembre de 2015.

Extractos de entrevistas realizadas durante el trabajo de campo entre 2014 y 2015.

Archivo de la Dirección de Patrimonio Municipal. Primer informe de la CEPHCyN. 08/06/2005.
} 


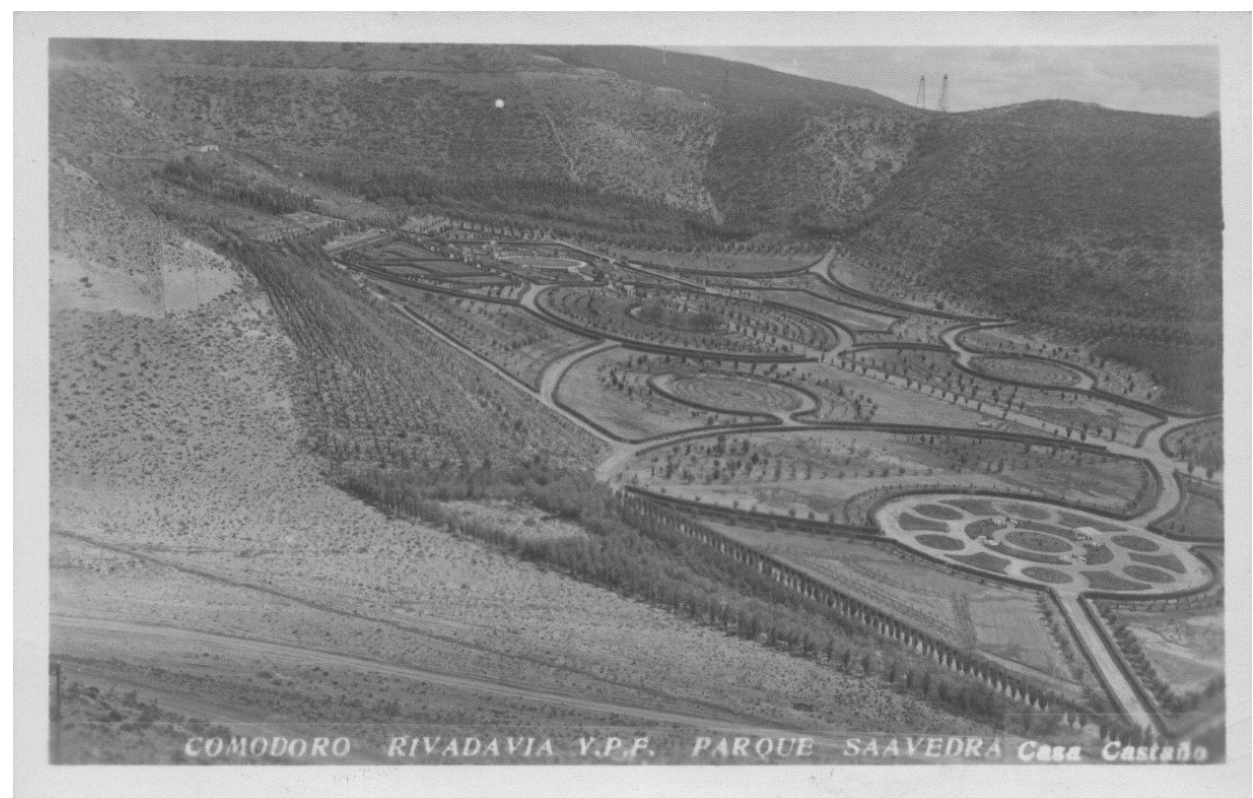

Fig. 5. El Parque como paisaje cultural. Fuente: Casa Castaño. Archivo Histórico Municipal.

El Parque Saavedra es un paisaje con pertenencia social depositario de un gran valor cultural en términos de la Carta de Burra que permite medir su significatividad como soporte de la memoria y la identidad ypefeana y la autenticidad del mensaje original representado por la historicidad del objeto en relación al conjunto donde está inserto según lo establece la Carta de Brasilia.

Es un bien cultural ambiental factible de gestión estatal dada la función social que éste debe cumplir, como lo han apuntado las Normas de Quito y los Principios de La Valeta. El Parque Saavedra permite ser leído a partir de varias Cartas más: la Carta de Florencia que permite reconocerlo como obra de arte en tanto contiene en su interior un Jardín histórico y la Carta de Washington en tanto todas las ciudades históricas poseen un paisaje histórico implícito en ellas, que es percibido y permite comprender la inserción de un asentamiento histórico en su contexto territorial. En el caso analizado los pozos petroleros fueron espacios para la producción y organizadores del espacio social y recreativo, por lo tanto, sirven para definir el carácter de ciudad histórica. Más allá de algunas alteraciones al diseño original, el Parque aún presenta condiciones de autenticidad e integridad tal como lo plantea el soft law, derecho no vinculante emanado de organismos internacionales que constituyen guías interpretativas para la gestión y protección de la cultura.

\section{La aplicabilidad de las normas ante su declaratoria patrimonial}

La idea de paisaje como bien colectivo y micro bien del ambiente ha sido incorporada paulatinamente en el derecho argentino a partir de la Convención de Río 92 y del reconocimiento 
constitucional en la Reforma de 1994 y en tratados de derechos humanos que protegen derechos fundamentales como a la participación en la vida cultural ${ }^{14}$ y el derecho humano al ambiente. Desde ese momento no hay sólo derechos -acceso a la información, la participación pública o ciudadana y acceso a la justicia- sino también deberes tendientes a la protección de bienes de uso y disfrute colectivo, como los bienes culturales.

El art. 41 de la Constitución Nacional es la norma central que reconoce el derecho a un ambiente sano y el deber de preservarlo, establece las funciones estatales obligatorias que permitan su protección y encomienda a la Nación dictar las normas que contengan los presupuestos mínimos de protección y a las provincias las necesarias para complementarlas sin alterar las jurisdicciones locales. Protección que comprende los ecosistemas naturales, pero también la actividad antrópica, es decir, los bienes ambientales y culturales en tanto configuran derechos de incidencia colectiva que brindan una amplia legitimación para obrar en su protección preventiva (Ciselli, 2011).

En cumplimiento del mandato constitucional, la Ley 25675 General del Ambiente del año 2002 (LGA) estableció principios e instrumentos de la política ambiental nacional (ordenamiento ambiental del territorio, la EIA, el sistema de control sobre el desarrollo de actividades antrópicas, la educación ambiental, diagnóstico e información ambiental y el régimen económico de promoción del desarrollo sustentable) a seguir por los legisladores provinciales, las administraciones locales e incluso para que la sociedad esté informada y pueda participar en los procesos de decisión.

Introdujo, además, la categoría daño ambiental colectivo como herramienta complementaria para medir el impacto de cualquier actividad en una comunidad, en un barrio, con variables como participación (movilización, opinión, encuesta, observación, aparición en medios), historicidad del bien (relación movilización con valor identitario del bien), calidad de vida. Con los datos analizados se encararía un Estudio de Impacto Vecinal: descripción, identificación del impacto, alternativas, medidas protectoras, sistema de vigilancia para luego elaborar un Informe de Impacto Vecinal. Dicho Estudio podría ser promovido por las Comisiones Evaluadoras o la Dirección General de Patrimonio Cultural provincial, ONGs, universidades, asociaciones vecinales, asambleas, es decir, por instituciones públicas o privadas o cualquier persona interesada en la temática.

Es decir que para el año 2005, cuando se firma el comodato entre el municipio local y el ente gremial, existía en el país, en la provincia y en el municipio normativa que podía referenciarse para fundamentar la importancia del Parque como lugar con valor patrimonial. La Comisión Evaluadora de Patrimonio, además, reconocía a través del Dictamen N02/2007 que "el criterio de valorización se basa en la importancia del Parque como espacio de reencuentro y reafirmación de la identidad local por su carácter de bien histórico-social”15.

14 Ej. Declaración Americana de Derechos y Deberes del Hombre en su art. 13, la Declaración Universal de Derechos Humanos en el art. 27, el Pacto Internacional DESC en el art. 15.

15 Información facilitada por Marcelo Gavilán, Director General de Patrimonio Cultural y Natural Municipal en 2006. 
Antecedentes que salieron a la luz y se activaron ante la firma del Convenio de Comodato entre la Municipalidad de Comodoro Rivadavia y el Centro de Empleados de Comercio y dieron fundamento a la acción de amparo promovida por la historiadora y ciudadana comodorense Gabriela Lencinas que pretendía proteger el diseño paisajístico del Parque Saavedra. Además, cuestionaba que fuera convertido en un espacio recreativo para "exclusivo disfrute de los empleados de comercio y sus familias”, violando el destino público exigido por el Convenio de Transferencia de Bienes del Estado.

El Juez de Primera Instancia hizo lugar a la acción de amparo argumentando que:

[...] El caso encuadra, dentro de los intereses difusos, amparados por la Constitución Nacional y la Constitución Provincial, hay un interés común a satisfacer, como lo es el derecho a preservar el Patrimonio Cultural e Histórico de la Provincia, y el Parque Saavedra, es patrimonio histórico y paisajístico de nuestra ciudad. Se encuentra afectado el derecho de preservación de ese patrimonio histórico municipal [...] Según los arts. 113 de la Constitución Provincial y 30 de la Carta Orgánica Municipal, está en cabeza del municipio la protección de los bienes históricos de la ciudad [...]

El art. 113 de la Constitución refiere a los bienes culturales y al derecho-deber de los habitantes de protegerlos y al deber de conservarlos por parte del Estado dado el valor que tienen para la identidad provincial.

Desde la jurisprudencia también existen antecedentes donde se aplica la legislación ambiental para la protección del patrimonio cultural a partir de la operatividad del artículo 41 y de la legitimación amplia prevista en el artículo 43 de la Constitución Nacional, con la acción de amparo cuando se trata de bienes colectivos. Ésta habilita ante la existencia de un interés difuso o colectivo, un acto u omisión ilegítima y un perjuicio a la comunidad. La amplitud de la legitimación activa está comprobada en diversos fallos donde se vieron afectados bienes culturales ambientales como en "Las Nereidas", "Sociedad de Fomento Cariló”, “Casa Millán”, “Caso Halabi” o "Casa Mansilla”. En Chubut el aspecto procesal de la acción de amparo está regulado por Ley 4572. Por otra parte, el daño moral colectivo a los valores culturales colectivos ha sido incorporado hace casi dos décadas a través del leading case Municipalidad de Tandil c/ transportes automotores la Estrella S.A. por daños provocados al grupo escultórico Las Nereidas y Defensoría del pueblo de CBA C GCBA (Casa Millán).

En la acción de amparo presentada por el Parque Saavedra se había ejercido el derecho a preservar un bien colectivo de valor cultural e identitario para la población. Sin embargo, la falta de declaratoria formal como Patrimonio Histórico, Cultural y Natural de la ciudad de Comodoro Rivadavia que recién llegó en $2008^{16}$ le sirvió al juez para desestimar finalmente la acción planteada. En este sentido la regla es que la protección de determinados bienes está

16 Ordenanza 9192/08; Resolución № 780/08 y Dictamen 02/07 de la CEPHCyN. 
subordinada a su expresa consideración como pertenecientes al Patrimonio Cultural (por medio de ley, acto administrativo, ordenanza, etc.) que disponga la calificación o registro respectivos, según el régimen de que se trate y que no puede suplirse por la decisión de un juez. Excepcionalmente, la jurisprudencia admite, con respecto a ciertos bienes carentes de tal declaración formal, pero portadores de indisputables valores [...] que se reivindique el derecho a su tutela, en razón del interés público comprometido y del deber jurídico general [...] por ser representativos de la vida social y cultural de la comunidad.

El nuevo Código Civil y Comercial Argentino -vigente desde agosto de 2015- incorpora los bienes de incidencia colectiva en su art. 14 y en los arts. 240 y 241 exigiendo compatibilizar el ejercicio de los derechos individuales con los bienes de incidencia colectiva, teniendo en cuenta su funcionalidad social, más allá de su valor económico. El artículo 240 refiere a que son bienes colectivos de una pluralidad de titulares que tienen derecho al uso y goce común, son indivisibles, no susceptibles de apropiación exclusiva y pertenecientes a la esfera social -ni público ni privado- (lo dijo ya la Corte en 2006 en el Caso Mendoza). Además, ellos poseen el status normativo para que sean calificados de jurídicos y susceptibles de protección.

El artículo 240 implica un reconocimiento a lo planteado por la Corte Suprema acerca de los derechos de incidencia colectiva, especialmente en el leading case Halabi importante en materia de legitimación procesal colectiva. Asimismo, brinda una nueva valoración a los recursos naturales que gira en torno a los beneficios -no estrictamente económicos- sino a los servicios ambientales -necesarios para la subsistencia y la calidad de vida de todos los seres humanos-. Cabe recordar que los valores paisajísticos y los recursos escénicos constituyen algunos de estos servicios ambientales reconocidos. Es decir que se trataría de bienes culturales ambientales colectivos que por sus características llevan implícitos un valor que merece ser protegido por el ordenamiento jurídico, conforme a las normas de derecho administrativo nacional y local dictadas en el interés público sin afectar el funcionamiento ni la sustentabilidad de los ecosistemas, la biodiversidad, los valores culturales y el paisaje. Es decir que el régimen del nuevo Código complementa lo que no está regulado en la Ley General del Ambiente y ante un conflicto de normas se respeta la jerarquía de los presupuestos mínimos.

El régimen hermenéutico jurídico dispuesto por el nuevo Código Civil y Comercial Argentino en su Título Preliminar busca la armonización de las categorías inauguradas con la Reforma del 94 al introducir, de manera expresa, la necesidad que el operador jurídico, dentro de un análisis sistémico y completo de todo el ordenamiento, tenga en cuenta «las disposiciones que surgen de los tratados sobre derechos humanos» -el derecho ambiental, es un derecho humano-, los principios y los valores jurídicos -el derecho ambiental tiene principios propios- y como anclaje de determinación a los bienes y valores colectivos ${ }^{17}$. El “diálogo de

17 "Fundamentos del Anteproyecto de Código Civil y Comercial de la Nación” elaborados por la Comisión de Reformas integrada por el Dr. Ricardo Lorenzetti, la Dra. Elena Highton de Nolasco y la Dra. Aída Kemelmajer de Carlucci (elDial.com- CC3COE) 
fuentes" entre la Constitución, el Derecho Público y el Derecho Privado, la utilización de reglas, principios y valores que se impone al operador jurídico (en especial, al juez pero también para el ejercicio del derecho de los ciudadanos) es una de las características más importantes del Título Preliminar y sus lagunas pueden ser llenadas con principios de derecho, entre los cuales se destacan conforme el Artículo $4^{\circ}$ de la LGA, los principios preventivo, precautorio, de sustentabilidad, de equidad intergeneracional, y de responsabilidad ya mencionados.

A nivel municipal, el reconocimiento del art. 123 de la Constitución Nacional ha ampliado la capacidad de los gobiernos locales para tomar decisiones, coordinar y gestionar sus recursos. La Constitución de Chubut coloca entre las competencias municipales la reglamentación de la preservación del ambiente y del patrimonio cultural. En este marco normativo, el Municipio de Comodoro Rivadavia sancionó su Carta Orgánica en 1999 estableciendo que el gobierno local es el responsable de fomentar la creación, producción y circulación de bienes culturales en tanto elementos que contribuyen al fortalecimiento de la identidad y tiene la facultad de proyectar, concertar y ejecutar acciones referidas tanto al patrimonio como al paisaje de la ciudad ante la elaboración de planes urbanísticos.

Antes de la sanción de la Carta Orgánica, en 1985, por Ordenanza 2625 se había creado la Comisión Evaluadora de Patrimonio Natural y Cultural como asesora del gobierno local. Ésta fue modificada por Ordenanza 11533/2014 en concordancia con el art. 41 de la Constitución Nacional y la Carta Orgánica Municipal quedando como asesora tanto del Poder Ejecutivo como del Legislativo con dictámenes de carácter vinculante, siendo la única de estas características en la provincia del Chubut. La misma contempla, además, nuevos criterios de valoración que tienen como base el soft law y las convenciones internacionales, incorpora como nueva categoría al paisaje tanto excepcional como cotidiano, amplía las funciones de la Comisión en lo referente a la gestión e intervención sobre el patrimonio, a la actuación para promover la participación ciudadana en la selección de bienes y acuerdos con los propietarios de bienes declarados como patrimonio cultural de la ciudad en pos del cumplimiento de la función social de la propiedad y con otros organismos para la realización de trabajos conjuntos, en la difusión y protección del patrimonio.

Además de las Declaratorias impulsadas por la Comisión Evaluadora y sancionadas por el Concejo Deliberante son importantes los inventarios, documentos de carácter descriptivo y prospectivo, con valor como elemento probatorio por constituir información sistematizada y de utilidad pública. A la hora de tener que confeccionar una ficha de inventario se ha planteado la importancia de la descripción densa (Geertz, 2000) de bienes culturales como herramienta metodológica valiosa, en tanto permite el trabajo de campo, el acercamiento a la perspectiva, las opiniones, representaciones y percepciones de los actores relacionados con determinado bien, su estudio exhaustivo y detallado y la interpretación de su significado dentro de un tejido cultural y territorial más amplio.

Los instrumentos más efectivos para la protección del patrimonio paisajístico derivan de una efectiva legislación ambiental, unida a la protección que otorgan las leyes de la cultura 
y la legislación urbanística. Todos los instrumentos deben ser debatidos con los habitantes, quienes deben contar con un alto nivel de información ya que su calidad de vida podrá verse afectada. En el Municipio de Comodoro Rivadavia aún está en debate el Código de Desarrollo Urbano que propone un modelo de ocupación territorial y un plan de desarrollo sustentable de la ciudad y que se encuentra en estrecha relación con lo planteado por la Ordenanza de ambiente que incluye la protección del paisaje.

Es decir que, desde el año 2008 en que se produjo la declaratoria del Parque como patrimonio paisajístico y a partir de la interpretación hermenéutica del ordenamiento jurídico argentino entendido como un sistema de normas interrelacionadas que respetan la jerarquía constitucional, se puede apelar a diversas herramientas para la preservación y gestión del mismo (Ciselli, 2018). La noción participación ciudadana que se tradujo en movilizaciones pro defensa de bienes con alto valor patrimonial desarrolladas entre los años 2009 y 2017 dio cuenta de la efectividad de las normas legales y de la apropiación que de ella hizo la población interesada en el tema.

La existencia del Convenio de Comodato y sus sucesivas prórrogas que llegan hasta el año $2042^{18}$ permite mostrar cómo se activaron las identidades sociales en la defensa de un bien representativo de un sector social de la población, pero también cómo lentamente se fueron desactivando con el transcurrir de los años y las apropiaciones que de dicho espacio fueron realizando otros sectores de la comunidad.

Más allá de ello existen alternativas para un efectivo tratamiento del patrimonio paisajístico que aparecen como posibles luego de la declaratoria del Parque Saavedra y de la política del gobierno municipal de patrimonializar barrios de la ciudad con pasado petrolero. Justamente se plantean como ideas, bosquejos, anteproyectos, ya que algunos de ellos exigen de la conformación de equipos técnicos y de discusiones con diversos actores. La propuesta gira en torno a dos ideas:

1-Incorporar estrategias de gestión que incluyan Planes de Manejo en el Parque. Cabe aclarar que en las renovaciones del convenio firmado en 2012 (donde se lo prorrogó por 10 años) y en 2016 (fecha del vencimiento original) se remarca que el gremio ha "cumplido con sus obligaciones e incorporado inversiones en el predio y que para poder concluir y amortizar mínimamente las obras” resulta necesario ampliar el plazo del convenio. El comodatario se compromete a "preservar las especies y las mejoras existentes", no apareciendo en el convenio mención alguna al valor paisajístico del Parque. Por ello, la propuesta de un Plan de Manejo se presenta como una modalidad de gestión bastante usual en las áreas naturales protegidas y con antecedentes a nivel urbano, en las reservas municipales. Éste debería definir para el Parque: un área histórica paisajística protegida; áreas libres destinadas al deporte, otras a la recreación (fogones, pistas), vías de circulación, zonas de vigilancia, zonas de juego, zonas para nuevas construcciones (salones, centro de interpretación), poniendo especial cuidado en

18 http://www.concejocomodoro.gob.ar/wp-content/uploads/2018/11/13997-2018-Comodato-del-ParqueSaavedra-4-10.pdf 
el tipo de intervención que se haría y no del modo en que actualmente se están construyendo las obras que sólo dañan el diseño original. Desde el punto de vista organizativo, el Plan de Manejo debería instalar una estructura institucional de cogestión y coparticipación entre organizaciones (Centros de Jubilados, Asociaciones Vecinales, ONGs), académicas (UNPSJB, Comisión Evaluadora, Colegio de arquitectos e Ingenieros), gubernamentales (de diversas direcciones o secretarías), a las que debe sumarse el comodatario (CEC). En forma paralela se debería redactar un proyecto de Ordenanza para el Plan de Manejo del Parque y su partida presupuestaria, en la cual podrían solicitarse fondos provenientes, por ejemplo, de la Responsabilidad Social Empresaria.

2-Considerar las estrategias de gestión e intervención propuestas por la Comisión Evaluadora como ente asesor no sólo del municipio sino como organismo de control tanto del Parque Saavedra como del patrimonio de la ciudad y desde 2014 con dictámenes vinculantes. Esta comisión técnica puede cumplir un rol central en la elaboración del Plan de Manejo. Desde el inicio del Convenio de Comodato, ésta ha realizado numerosas propuestas al Centro de Empleados de Comercio referidas a: la conformación de un Centro de Interpretación, diseño de los senderos interpretativos, el trabajo conjunto con las distintas facultades de la UNPSJB, la formación de equipos interdisciplinarios e intersectoriales, la convocatoria a vecinos del Parque, asociaciones vecinales, ONGs y ex ypefeanos para que participen en la gestión cultural, la invitación a las instituciones educativas para que incluyan al Parque dentro de la currícula escolar como patrimonio paisajístico de la ciudad, la difusión en los medios locales y regionales acerca del patrimonio de la ciudad. Propuestas que aún no han sido debatidas.

Así como la apropiación social del Parque Saavedra como patrimonio histórico y paisajístico de la ciudad tiene múltiples aristas, sin dudas, su gestión es compleja. La configuración barrial se caracteriza por la coexistencia de ex ypefeanos y sus familias con nuevos migrantes que desconocen la ciudad y su historia o jóvenes no vinculados a la empresa petrolera estatal y con una valorización diferente a quienes fueron parte de esa historia vivida. Los actuales usos sociales del Parque muestran su importancia como espacio verde público que favorece la calidad de vida de la población comodorense dado que es un espacio propicio para el deporte, la recreación y el esparcimiento con una relación estrecha con su entorno y con la trama urbana de la ciudad de Comodoro Rivadavia. Sin embargo, para un mejor conocimiento del diseño del Parque y su gran significación histórica, cultural y paisajística inserta en el sistema ypefeano aún queda un largo camino por recorrerse.

\section{CONCLUSIONES}

El Parque Saavedra, como referente empírico, permite el acercamiento a los modos en que los ex ypefeanos y comodorenses perciben el paisaje cotidiano en su mínima escala territorial y construyen sus identidades socio territoriales al conferirles un "sentido de lugar", 
de pertenencia y de identidad espacial que identifica una historia común y unos valores compartidos. Más allá de su diseño, forma parte de un proceso histórico social más amplio relacionado con los usos del tiempo libre y las características propias del mundo laboral petrolero construido en el sistema Y.P.F. Es esa dimensión histórica y social la que permite comprender su consideración como elemento identitario de la ciudad y su declaratoria como Patrimonio Cultural Municipal.

En la actualidad su potencial como bien patrimonial deriva de su triple valor:

- simbólico porque como objeto histórico es vehículo portador de mensajes, ya que representa el estado de bienestar y beneficios sociales ofrecidos por la empresa petrolera para sus trabajadores/empleados y sus familias y simboliza las relaciones entre las personas que los produjeron y los actuales usuarios- receptores. La sigla Y.P.F., que aún aparece en la trama paisajística, es uno de los símbolos identitarios que conectan al Parque, los ypefeanos y la empresa y en la actualidad representan esa época.

- formal porque la majestuosidad de su trazado despierta los sentidos de quienes disfrutan este espacio verde con historia.

- de uso, por la utilidad que brinda a la comunidad o a determinados sectores sociales como espacio recreativo, social, educativo y turístico.

Los actores sociales han construido representaciones según su vinculación personal con la historia del Parque Saavedra que pueden convertirse en hegemónicas o subalternas pero que implican procesos de interpretación relacionados con sus propias historias, sin embargo, el real aprecio por el Parque Saavedra va a lograrse en la medida que los comodorenses se apropien simbólica y afectivamente de él y logren darle significado. Por lo antedicho, instalar la importancia del Parque como patrimonio paisajístico es un desafío para cualquier gestión que se realice sobre él, para lo que es importante modificar la idea de que es sólo un espacio verde recreativo o un camping. Por otra parte, la elaboración de un Plan de Manejo aparece como la mejor estrategia de acción viable a corto y mediano plazo y con importantes antecedentes en el Sistema de Áreas Protegidas de la Argentina.

La declaratoria del "Parque Saavedra" colocó en la agenda pública la necesidad de elaborar una política patrimonial que protegiera los bienes culturales ambientales luego de varias movilizaciones de vecinos que reclamaron no sólo por la defensa del Parque sino por otros bienes considerados representativos de la ciudad. Asimismo, motivó decisiones políticas tales como dos Ordenanzas que reconocen a los dictámenes de la Comisión Evaluadora de Patrimonio como vinculantes y declaran como patrimonio histórico cultural de la ciudad a los barrios con pasado petrolero.

Asimismo, es necesario impulsar la idea que los bienes culturales ambientales deben 
formar parte de "políticas de percepción social del patrimonio histórico, de su conservación y del orgullo de su difusión y disfrute", tarea compleja de gestión cultural que reconoce el rol de la participación de la comunidad, la prensa con su difusión y la educación formal y no formal en la valoración histórica y cultural de los bienes.

\section{REFERENCIAS}

Besse, J. M. (2006). Las cinco puertas del paisaje. Ensayo de una cartografía de las problemáticas paisajeras contemporáneas. En J. Maderuelo (Ed.), Paisaje y pensamiento. Madrid: Adaba. Cardoso de Oliveira, R. (2004). El trabajo del antropólogo: mirar, escuchar, escribir. Revista de Antropología Avá, 5.

Ciselli, G. (2011). El patrimonio entre identidad y ambiente. Revista electrónica de Patrimonio Histórico, 9. http://revistaseug.ugr.es/index.php/erph/article/view/3403/3414

Ciselli, G. (2018). Diálogos de la Historia y la Antropología con el Derecho Ambiental acerca del Patrimonio Paisajístico. Río Gallegos: UNPAedita.

Ciselli, G., \& Enrici, A. (2012). En torno al valor histórico-paisajístico del Patrimonio Cultural. El caso del Parque Saavedra en Comodoro Rivadavia. Historia Pasado Por-venir, 6, 1940.

Ciselli, G., \& Hernández, M. (2015). El patrimonio industrial como la huella del trabajador petrolero en el territorio. El caso de Y.P.F. en Comodoro Rivadavia y su impronta cultural. Buenos Aires: Eitorial Dunken.

Ezpeleta, R. (Dir.) (1957). Medio siglo de petróleo argentino. 1907-1957. Comodoro Rivadavia, Ed. El Rivadavia.

Frolova, M. (2009). La evolución reciente de las políticas de paisaje en España y el Convenio Europeo del Paisaje. Revista Proyección, 9.

Geertz, C. (2000). La interpretación de las culturas. Barcelona: Gedisa.

Guber, R. (2001). La etnografía. Método, campo y reflexividad. Buenos Aires: Grupo editorial Norma.

Guber, R. (2004). El salvaje metropolitano. Reconstrucción del conocimiento social en el trabajo de campo. Buenos Aires: Paidós.

Lorenzetti, R. (2005). El paisaje: un desafío en la teoría jurídica del derecho ambiental. En Edición Homenaje a Jorge Mosset Iturraspe, Santa Fe, Universidad Nacional del Litoral.

Lorenzetti, R. (2009). Teoría del Derecho Ambiental. Buenos Aires: Edic. La Ley.

Mata Olmo, R. (Coord.) (2009). Evaluación del paisaje de la Comunidad de Madrid: de la protección a la gestión territorial. Urban, 14.

Prats, Ll. (1997). Antropología y patrimonio. Barcelona: Editorial Ariel.

Prieur, M. (2011). Conferencia "El patrimonio común de la Humanidad y la protección del paisaje”, en II Jornadas de Patrimonio Cultural, Derecho Ambiental y Urbanismo del Litoral, Universidad Nacional del Litoral. Santa Fe. 
Rodríguez, J. (1998). La Ciencia del Paisaje a la luz del paradigma ambiental. Revista Trimestral Geonotas, 2(1).

Santos \& Ganges, L. (2002-2003). Las nociones de paisaje y sus implicaciones en la ordenación, en Ciudades. Revista del Instituto Universitario de Urbanística de la Universidad de Valladolid, 7, 42-43.

Serrano, D. (2007). Paisaje y políticas públicas. Investigaciones geográficas, 42, 109-123. 